\title{
Review on Multi Level Inverter Topologies and Control Strategies for Solar Power Conversion
}

\author{
B. G. Shivaleelavathi ${ }^{1}$, Chinmayi ${ }^{2}$, Veeramma Yatnalli ${ }^{1}$ \\ ${ }^{1}$ Department of Electronics and Communication Engineering, \\ JSS Academy of Technical Education, Bengaluru, \\ Visvesvaraya Technological University, Belagavi, Karnataka, India \\ 2Department of Electronics and Communication Engineering, \\ Jyothy Institute of Technology, Bengaluru, \\ Visvesvaraya Technological University, Belagavi, Karnataka, India \\ E-mail: shivaleelavathi@gmail.com, chinmayisrikanth@gmail.com, \\ veeramma71@gmail.com
}

Received April 25, 2020; Revised May 9, 2020; Accepted June 2, 2020

\begin{abstract}
Nowadays solar power has become an alternate method of power generation for standalone systems for both urban and rural electrification. The Power Electronics converters used for the power conversion should provide quality AC output to have near sinusoidal voltage. The inverter topology and the PWM technique of the inverter play a vital role in providing quality output. This paper reviews recent contribution to establish the current status and development of the technology to provide reader with an insightful review of multilevel inverters and its control strategy. A brief overview of Multi Level Inverters (MLI) topology and advantages of Cascaded H-Bridge Multi Level Inverter (CHBMLI) for solar power conversion is presented and the various control strategies for CHBMLI are discussed with view point of quality output. Among the different PWM techniques discussed, the Elliptical Multi Carrier PWM (EMC PWM) control strategy is the new modulation technique which successfully improves the DC bus utilization without overmodulation and without adding third harmonic to fundamental frequency. Also, the technique is successful in reducing the \%THD at the output voltage. The control strategy is simple even with increased level of output voltage, which is not possible in SVPWM technique. Hence, the EMC PWM technique is having better performance when compared to Multi Carrier PWM (MCPWM) technique, Space Vector PWM (SVPWM) technique and Third Harmonic Injection PWM (THIPWM) technique.
\end{abstract}

Keywords: Multi Level Inverter(MLI), CHBMLI, EMCPWM, Control Strategy. 


\section{INTRODUCTION}

In a developing country like India, where more than $60 \%$ of population resides in rural area, grid connection for electrification is not feasible resulting in less per capita energy consumption of the country. Rural electrification was given less importance because of villages located in difficult areas like hilly area, forests and deserts. The number of hours of power demand will be very less resulting into quite a low power demand. Also, the income level of villagers is so less to afford the electricity. Moreover the cost of connecting grid for remote rural electrification results in more transmission and distribution losses [1][2].

In this regard, solar power standalone system produces power independent of the grid which can be efficiently utilized for rural electrification. The cost of Photo Voltaic (PV) power is continuing to decrease with their increased efficiency implies a promising source of energy in the near future [3][4][5]. Figure 1 depicts basic the solar power conversion system. The Photo Voltaic (PV) array converts photo energy into DC Power. The diode ensures that the DC power converted from array flows towards the power conditioner. The power conditioner block consists of DC to DC convertor with Maximum Power Point Tracker (MPPT), a battery charge and discharge controller circuitry. This controller is used to prevent over charging / discharging of battery bank. The MPPT ensures the maximum power generation from solar PV array.

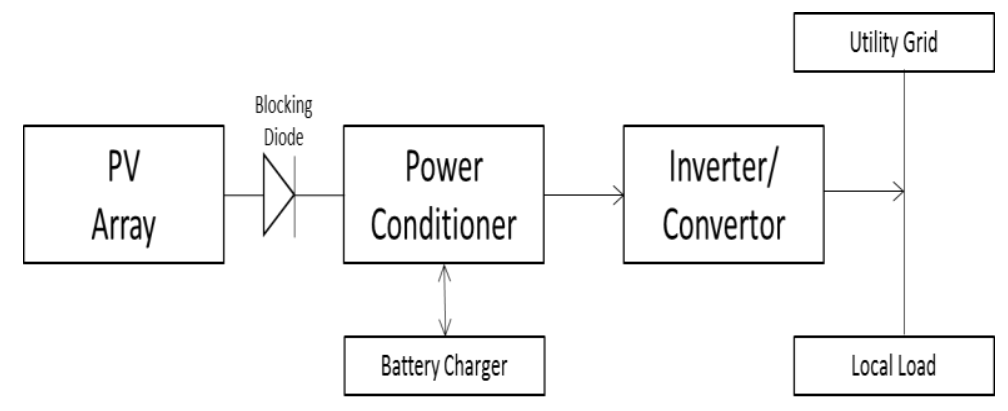

Figure 1. Solar power conversion system

The power generated from solar array depends on many factors such as: geographical location, local climate conditions, irradiance, temperature of solar cells, etc. The solar power generated is also the function of the product of voltage and current. By varying either voltage or current, power generated can be maximized. To ensure the delivery of maximum power from PV source, a controller circuit called MPPT is used. This controller circuitry ensures that PV array provides required amount of current for the operation at the maximum power point and the load is applied with the maximum power generated under the given atmospheric conditions. 
Inverters are crucial component in most PV systems commissioned in grid connected or distributed systems. The MLI performs power conversion in multi steps to obtain better power quality, reducing switching losses, improved electromagnetic compatibility and higher voltage capability. Considering the above advantages, MLI are in demand [6]. The various configurations of MLI generating incremental voltage waveshape and used for various utilization are "Diode Clamped MLI", "Capacitor Clamped or Flying Capacitor (FC) MLI", "Neutral Point Clamped (NPC) MLI", "Cascaded H-bridge(CHB) MLI", etc. [7]-[9].

In Pulse width Modulation Technique (PWM), the pulsating waveform duty ratio is controlled by modulating waveform. The intersection of modulating waveform and the carrier waveform decides the ON and OFF switching of the switches. Research shows that, single PWM techniques cannot be suited for different applications. Various PWM techniques have evolved in the field with advances in "Power Electronics devices and Microcontrollers". The above issues motivated the researchers to do intensive research in the PWM techniques since 1970's [10]. In three-phase inverter systems, "PWM strategy" plays an important role in minimizing the harmonics and switching losses. The modulation technique aim is to accomplish a variable output with highest fundamental component and minimum harmonics.

This paper furnishes a brief outline of Multi Level Inverters (MLI) configuration and advantages of "Cascaded H-Bridge Multi Level Inverter (CHBMLI)" for solar power conversion. The various control strategies for CHBMLI are discussed with view point of quality output. This paper suggests a new control strategy for CHBMLI that has improved power quality and well suited for solar power converters. The subsequent sections present the Multi Level Inverter topologies, Modulation techniques, Modulating signals, Summary of the literature review and conclusion in detail.

\section{MULTILEVEL INVERTERS}

Inverters play a key component in PV power system as it should provide quality AC output power as per the load requirement. Inverter is the most costly block of PV power conversion system and is the deciding factor in for overall system reliability and operation [11].

The inverter produces AC output that can be pure sinusoidal wave, quasi sine wave, and square wave. The efficiency of pure sinusoidal wave inverters are high and produce high power quality output. The inferior power quality and the existance of \% THD in modified "sine wave", "square", and "quasi sine wave" has an effect on the performance of the load connected to the inverter output. Hence, the pure sine wave inverters are selected for augmenting the output power quality that increases the life of the loads. 


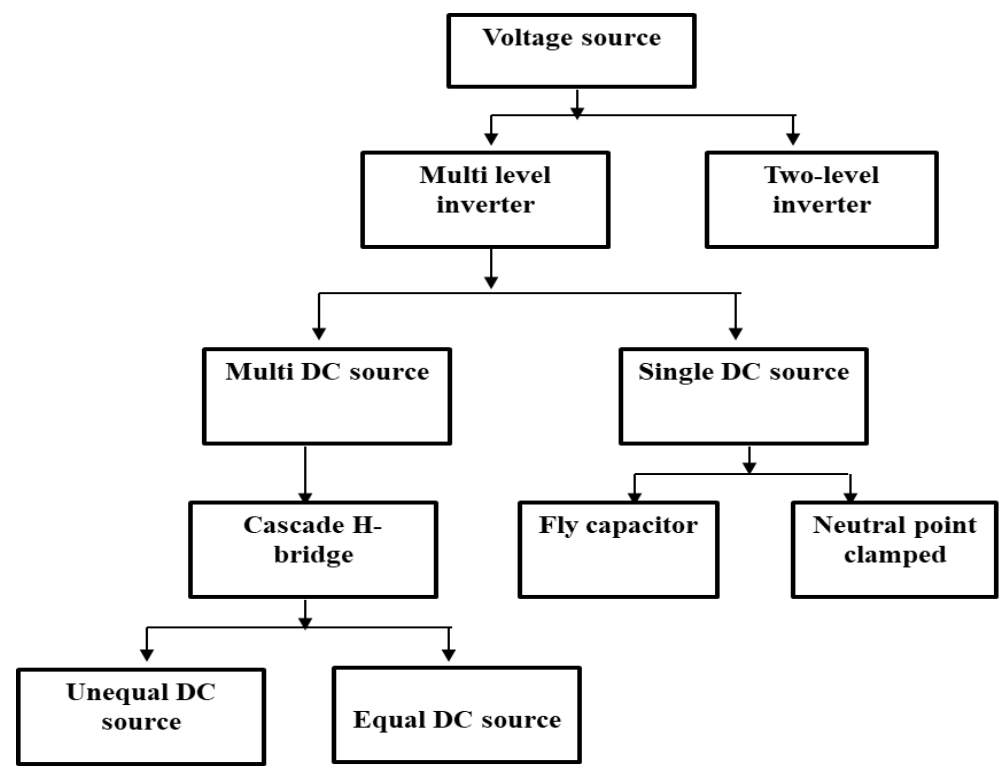

Figure 2. Multilevel inverter classification

To accomplish the pure sinusoidal wave output at the inverter, MLI are incorporated. The MLI, as the name says, has multilevel voltage steps at the output to obtain sinusoidal voltage with improved electromagnetic compatibility, lower switching losses, and higher dv/dt capability. The MLI increase the power by $(\mathrm{m}-1)$ times than of the conventional two level inverters, where " $\mathrm{m}$ " is the number of output level of the inverter [12] [13]. The classification of multilevel inverters is shown in Figure 2.

The advantages of MLI are [14]-[15]:Reduced THD in output voltage, Low switching stresses on power switching devices, Suites for medium and high voltage applications, Higher voltage levels are produced, Low Electromagnetic Interference (EMI) due to reduced dv/dt, MLI generates the output voltages with low distortion, Operates at both higher switching frequency and fundamental switching frequency.

MLI Require more components and control strategy becomes complex as the number of output level increase. MLI are extensively used in medium and high voltage applications such as [16]: Flexible AC transmission systems (FACTS), HVDC transmission, VAR compensation, Active filters, AC drives, Electric vehicle systems, Hybrid vehicle systems, Distribution Generation Systems, Adjustable Speed Drives, and Renewable Energy Power Generation. The commercially existing MLI topologies are [7] - [8] :

- Neutral Point Clamped (NPC) or Diode clamped topology

- Flying Capacitor (FC)

- Cascaded H-Bridge (CHB) 


\subsection{Diode Clamped Multi Level Inverter (DCMLI)}

To produce multilevel AC voltage output, the DCMLI topology uses clamping diodes and cascaded DC capacitors. For an m-level output voltage of a DCMLI, for each leg, $(\mathrm{m}-1) *(\mathrm{~m}-2)$ clamping diodes, $(\mathrm{m}-1)$ DC linked capacitors and $2(\mathrm{~m}-1)$ switching devices are required. The blocking diodes required are quadratically associated with the output voltage levels. The increased number of voltage level improves the quality of the output voltage and the output voltage waveform turns out to be near sinusoidal. Figure 3 shows the circuit composition for 5-level DCMLI [16].

For an m-level, the voltage across each capacitor at steady state is $\mathrm{V}_{\mathrm{dc}}$ / (m-1), where Vdc is DC bus voltage. The switching devices in DCMLI, block only DC bus voltage Vdc and clamping diodes are required to block reverse voltage. Hence the diodes of different ratings are used. For increased level of output voltage, the voltage balancing across the capacitor becomes challenging. Also, the increase in number of switching devices, DC capacitors and clamping diodes results in complex configuration of circuit. In this topology, each switching device has different conduction periods, resulting in dissimilar current ratings of the switching devices. This development results in unequal heating in switching devices leading to additional losses in stressed devices and limiting the output power and switching frequency of the converter. When DCMLI switches are controlled by PWM technique, they suffer from unequal load distribution among them. As the number of output level increases, there is an increase in the number of devices resulting in complicated design and execution of topology.

\section{The advantages of DCMLI are:}

- Increase in the number of output level, reduces the harmonic content and output filters can be avoided.

- As the devices are switched at fundamental frequency, DCMLI have high efficiency.

- The control strategy is simple.

\section{The disadvantages of DCMLI are:}

- As the number of diodes required is quadratically associated to the number of output levels, the circuit becomes bulky.

- As the conduction period of switching devices differs, the current rating of the switching devices also differs.

- Control of active power flow of individual converter is difficult in MLI system. 


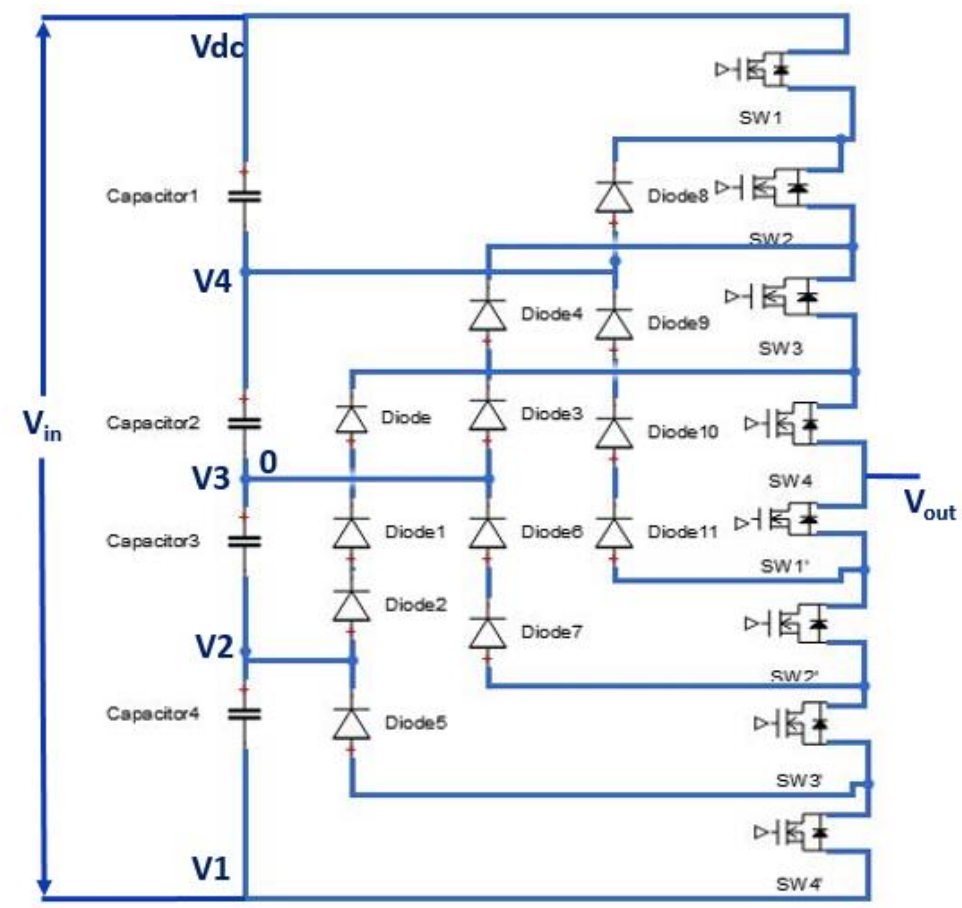

Figure 3. DCMLI topology for 5-level output[16]

The DCMLI are used in high power applications such as in traction, back-to-back intertie, adjustable speed drives, high voltage $\mathrm{DC}$ and $\mathrm{AC}$ transmission lines, reactive power compensation etc.

\subsection{Flying Capacitor Multi Level Inverter (FCMLI)}

This topology is almost similar to DCMLI except it uses clamping capacitors to alternative clamping diodes. Capacitors on the DC side are connected similar to ladder structure, wherein the voltage differs across each capacitor and subsequent capacitor. The voltage rise between the two contiguous capacitors legs results in increase in the output voltage levels. The advantage of FCMLI over DCMLI is phase redundancy for internal voltage levels that is, two or more effective switch combinations are probable to synthesize. Whereas, DCMLI has only Line to Line redundancy. Figure 4 shows topology for 5-level FCMLI [16]. For an m-level output voltage, $\{(\mathrm{m}$ $\left.1)^{*}(\mathrm{~m}-2)\right\} / 2$ auxiliary capacitors for each phase are required along with (m1) main DC link capacitors of the same rating. Increase in the number of levels, calls for additional number of storage capacitors which results in a bulky and costly topology as compared to DCMLI. 


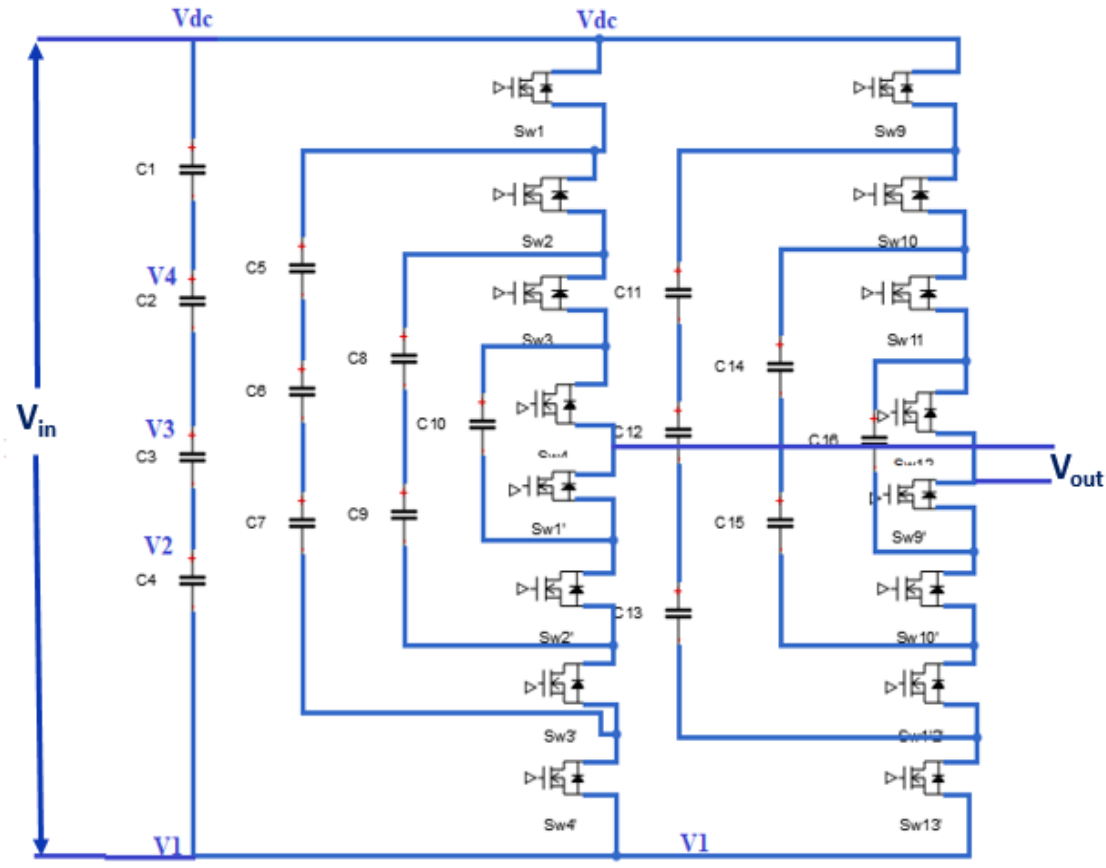

Figure 4. FCMLI topology for 5-level output [16 ]

The advantages of FCMLI are:

- Balancing the voltage levels of the capacitors is possible, because of flexible phase redundancy.

- As the number of output level increases, harmonic content reduces.

- Control of both active and reactive power flow.

\section{The disadvantages of FCMLI are:}

- Due to more number of storage capacitors, the circuitry is bulky and expensive.

- Complex control to maintain the capacitors voltage balance.

- Control strategy of Switches becomes complex for higher number of levels.

- As the number of voltage levels increases,Packaging becomes difficult.

\section{The applications of FCMLI are:}

These are used in Sinusoidal current rectifiers, Static Var generation, Induction motor control using Direct Torque Control (DTC) circuit etc.,

\subsection{Cascaded H-Bridge Multi Level Inverter (CHBMLI)}

To overcome the drawbacks of DCMLI \& FCMLI Fracchia [11] have proposed CHBMLI. Single H-Bridge cells are connected in series with multiple isolated DC supplies to produce multilevel waveforms. It has attractive features such as [12 ]: 
- Capable to reach higher power levels as well as output voltage levels.

- Using lower rating switching devices it can produce medium output voltage.

- Because of high degree modularity, the replacement of faulty modules is easy.

- As this topology does not require any capacitors and diodes, compared to other two topologies, the circuit layout is optimized and even packaging results in reduced cost

- Soft switching is possible to reduce the switching losses and device stresses.

- Capable of synthesizing output voltage waveform with reduced \% of THD.

Figure 5 depicts the cascaded H-bridge configuration to achieve 5-level output [16]. An m-level H-Bridge inverter has 2(m-1) power semiconductor switches, (m-1)/2 H-Bridge cells supplied with separate DC sources. The HBridges are connected in series fashion to attain the required m-level output. This CHBMLI produces near sinusoidal voltage wave shape with one time switching per cycle and reduced switching losses. As the number of output level increases, the \% THD reduces and the complexity of the control algorithm increases.

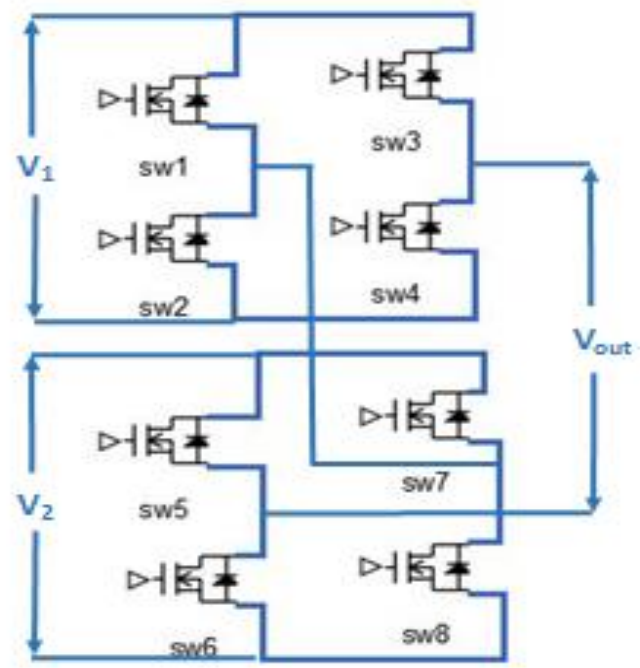

Figure 5. CHBMLI configuration for 5-level output [16]

\section{The advantages of CHBMLI are:}

- To produce the same level of output, this topology needs minimum number of devices when compared with other two topologies.

- To reduce the switching losses \& stresses, soft switching techniques can be used.

- In this topology, since each level has same structure, packaging is probable. 


\section{The disadvantages of CHBMLI are:}

- Applications are limited as it needs numerous separate D.C. sources.

- Switching arrangement should be in such a way that all DC sources can be charged equally.

\section{The applications of CHBMLI are [14]:}

- The CHBMLI are appropriate for high power medium voltage drives and for utility applications.

- Hybrid electric and Fuel cell vehicles.

- Traction drives.

- PV power generation

- In static Var generators.

\section{MODULATION TECHNIQUES}

The quality of the output voltage and power of multilevel inverter can be improved with the increase in the number of levels in the output [17 ]. With the increase in the output level, the harmonic content reduces and even the $\mathrm{dv} / \mathrm{dt}$ stress on the switches. The output power quality of the inverter can also be enhanced by proper selection of modulation technique. Vast research is going on to improve the converter efficiency with less \% THD in the output voltage waveforms for wide ranges of loading conditions. These can be achieved by having proper modulation strategies to control MLI. The main objectives of the modulation strategy are:

- Ability to operate with wide range of modulation index.

- To have improved overall efficiency of the converter with reduced switching losses.

- To have Reduced \% THD of output voltage.

- To obtain high value of output fundamental frequency component.

- Practical implementation of control strategy should be easy.

- Should be of less complex and less time consuming.

Based on the switching frequency, the modulation techniques are classified as shown in Figure 6 [18][19] 


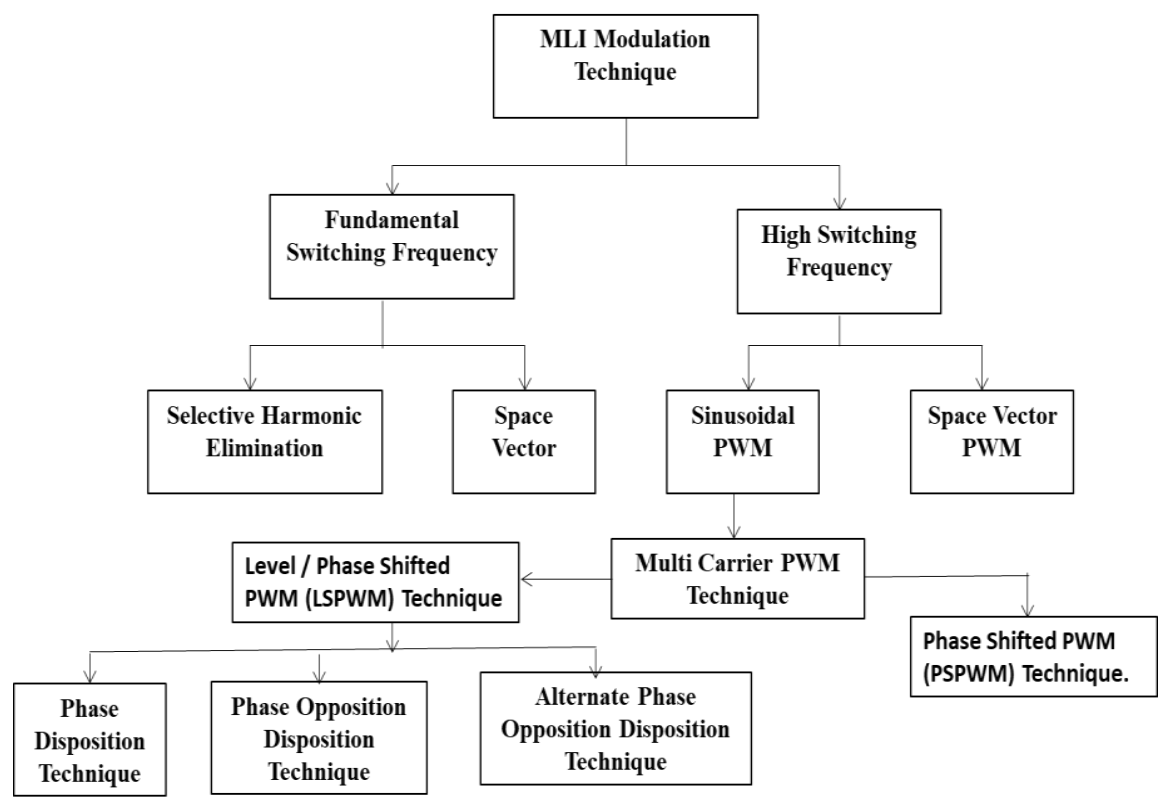

Figure 6. Classification of Modulation Technique

\subsection{Selective Harmonic Elimination (SHE) Technique}

The "SHE" basically involves elimination of selected harmonics in inverter output waveforms. The advantages of SHE Technique are [20]:

- It has direct control over output voltage harmonics with superior harmonic profile.

- Reduced switching losses as this technique works at fundamental switching frequency.

- The capacity to leave triplet harmonics in three-phase systems.

The above advantages leads "SHE" technique as an optimal choice in high power medium voltage drives, techniques involving power quality improvements, high voltage direct current transmission systems and distribution generation systems. The "SHE" scheme works based on the predesigned switching angles for multilevel inverter to obtain required output voltage by reducing desired order of harmonics.

The main obstruction for "SHE" method is solving highly non-linear transcendental equations set for switching angles, which results in prolonged computations, long computation time and increase in convergence time. Hence this modulation technique becomes more complex and tedious to implement for high level of outputs. Moreover, "SHE" technique provides highest power quality only at fundamental switching frequency [21][23]. Hence it is not suitable for high switching frequency operation. Also, it's difficult to eliminate other low order harmonics. 


\subsection{Space Vector PWM (SVPWM) Technique}

In "SVPWM" technique, an amalgamation of phase voltage levels is denoted as switching state. According to the Space vector theorem, each switching state is an instantaneous voltage vector composed of three-phase voltage levels. Graphically all the switching states organized together formulate a voltage hexagon lattice. Each node on the lattice denotes a producible voltage vector, few of the nodes having several redundant switching states. The controller assigns the time averaged voltage vector produced using these nodes. The voltage vector is attached to a stationary stator reference frame using Cartesian $\alpha \beta$ co-ordinate system. The chore of the modulator is to choose such switching states that encounter the reference. The advantage of this method is, whole area enclosed by the lattice can be used without considering modulation indices [25].

The advantages of SVPWM are [26] - [29]:

- Improved fundamental output voltage.

- Improved harmonic performance resulting in reduction of \%THD.

- Direct hardware implementation is simple on Digital Signal Processor (DSP).

\section{The disadvantages of SVPWM are:}

- The intricacy of selecting switching state and redundant switching states surges dramatically as the number of level increases.

- Cannot completely eliminate low order harmonics.

- Suitable only for three-phase MLI.

\subsection{Sinusoidal PWM (SPWM) Technique}

In SPWM technique, a modulating wave is compared with a triangular wave to produce the switching pulses. A MLI with $\mathrm{m}$ - level voltage requires (m-1) triangular carrier waves. Based on the arrangement of these carrier waves for MLI, the sinusoidal Multi Carrier PWM (MCPWM) Techniques can be categorized into 2 types: Level Shifted PWM (LSPWM) technique and Phase Shifted PWM (PSPWM) technique. Phase Disposition technique, Phase Opposition Disposition technique and Alternate Phase Opposition Disposition technique are the techniques classified based on the carrier arrangements in LSPWM technique.

MCPWM Technique involves sampling of a single modulating signal, having frequencies same as that of output frequency of the MLI through the several carrier signals typically being triangular waves of higher switching frequency. MCPWM Technique is the most popular PWM technique adopted for MLI [30] [31], because of its simplicity and ability to generate good quality of output voltage and current. As the number of levels in the output of MLI increases compared to other PWM techniques this technique is not much complex to implement and it can be easily implementable using digital controllers. 
The advantages of MCPWM techniques are [31] [32]:

- Very easily extendable to implement for higher level of output.

- Reduced \%THD compared to SHE technique.

- Good quality output at higher switching levels.

- Easy implementation in digital controller with less time consumption.

\section{The disadvantages of MCPWM techniques are:}

- Cannot eliminate lower order harmonics completely, resulting into filter requirements.

- Due to high switching losses at high switching frequency the efficiency is low.

- Poor DC bus utilization.

- Unequal power distribution.

With MCPWM technique, the maximum output voltage achieved is $75 \%$ of Vdc. To exceed this boundary, a third harmonic has to be injected to the modulating wave. By the SVPWM technique, this output can be achievable without adding third harmonics [29].

\section{MODULATING SIGNAL}

The modulating signal which is compared with reference signal, can be of pure sinusoidal wave or non-sinusoidal. If a pure sine wave is used as modulating wave, then the PWM is Pure "Sinusoidal PWM" ("SPWM") technique and if a third harmonic injected sine wave is used as modulating wave then the PWM is "Third Harmonic Injection PWM" ("THIPWM") technique. The "THIPWM" is considered as non-sinusoidal modulating wave.

\subsection{Pure Sinusoidal Modulating PWM}

The Pure "Sinusoidal PWM" is the well-established PWM technique in which triangular wave is compared against a sinusoidal modulating wave as shown in Figure 7 to generate PWM pulses [16].

The expression for the modulating wave $\mathrm{Vr}$ is:

$\mathrm{V}_{-} \mathrm{r}=\mathrm{Ar}_{\mathrm{r}} \operatorname{Sin}(\omega \mathrm{t})$

Where $A_{r}$ - is the amplitude of the pure "Sinusoidal Modulating Wave".

The carrier signal triangular wave $V c$ is having the amplitude of Ac with a frequency of $\mathrm{f}_{\mathrm{c} .}$. The "amplitude modulation index", ma is given by equation (2)

$\mathrm{m}_{\mathrm{a}}=\mathrm{Ar} / \mathrm{A}_{\mathrm{c}}$

The "frequency modulation index", mf is given by equation (3)

$\mathrm{m}_{\mathrm{f}}=\mathrm{f}_{\mathrm{c}} / \mathrm{f}$

Where $f_{c}$ is the frequency of the triangular carrier waves called switching frequency and $f$ is frequency of the modulating wave which sets the fundamental frequency of the inverter output voltage. 
The "SPWM" technique is a simple modulation technique for software coding or to implement on hardware. However, this technique does not fully utilize the DC bus supply voltage.

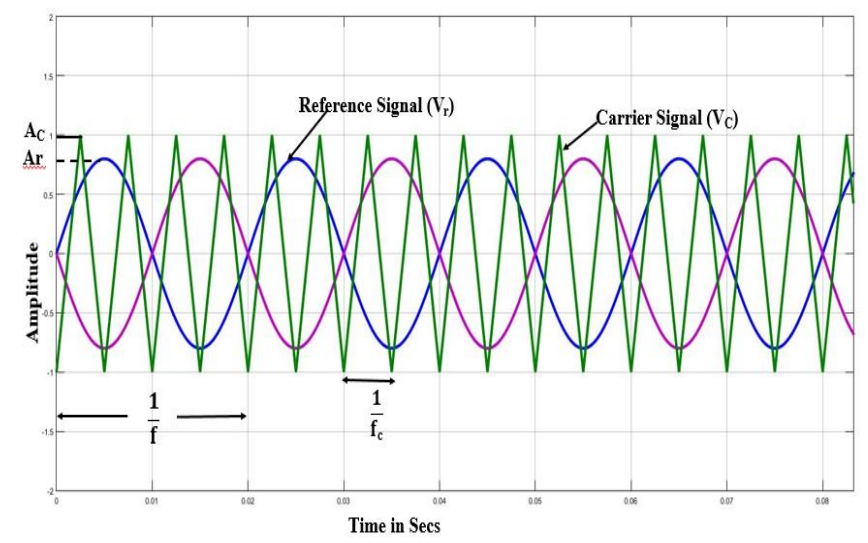

Figure 7. Pure Sinusoidal Modulating Wave PWM Technique[19]

\subsection{Third Harmonic Injection PWM (THIPWM)}

In this technique, "Third-Harmonic" is injected to traditional sinusoidal PWM as shown in Figure 8. Hence, the modulating AC waveform is non sinusoidal, consisting of both "fundamental component" and a "thirdharmonic component". This results in the peak-to-peak amplitude of the modulating wave not to exceed DC supply voltage, but the fundamental component of output is higher than supply voltage contributing $15 \%$ increase in output gain compared to pure sine technique.

The modulating waveform is defined as in equation (4) [16 ]:

$f(\omega t)=1.15 m_{a} \sin (\omega t)+0.19 m_{a} \sin (3 \omega t)$

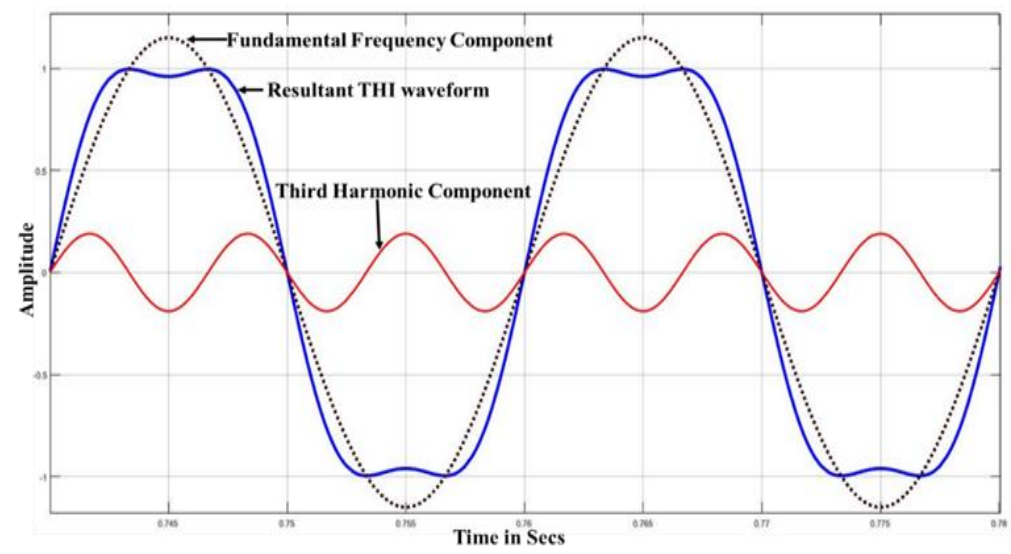

Figure 8. THIPWM Technique [19]

Even though the output voltage gain has increased, the drawback of "THIPWM" technique is that the modulating waveform has to be continuous 
irrespective of their shape, resulting in inability to provide any reduction in switching frequency compared to "SPWM".

\subsection{Elliptical Multi Carrier PWM Technique (EMC PWM)}

The research work carried in [33]-[37] present a novel modulating wave for MCPWM technique to address the issue of underutilization of DC bus in pure sine MCPWM technique. The authors propose a novel Elliptical modulating wave which is compared with carrier waves for generating PWM pulses for MCPWM technique (EMC PWM) [32] [34 ]. The performance of the CHBMLI is investigated using proposed novel EMC PWM technique. Fig. 9 shows the EMC PWM technique. The performance of this novel modulating wave is compared with conventional pure sine wave MCPWM technique [34]. The CHBMLI with proposed control strategy is employed to convert the power in solar power generation. The feasibility of the proposed control strategy demonstrated for both single-phase and three-phase CHBMLI. The simulation results are validated with experimental results [33]-[35]. The EMC PWM technique improves quality of the output power by increased DC bus utilization of $15 \%$ and also reducing the \%THD at the output.

The expressions used to generate the Elliptical Modulating wave are given by equation(5) and (6):

$\mathrm{X}=\mathrm{h}+\mathrm{r} \times \cos (\mathrm{t})$

$\mathrm{Y}=\mathrm{k}+\mathrm{V}_{\mathrm{m}} \times \sin (\mathrm{t})$

Where, in the equation (5) and (6),

$r$ - frequency term which is the radius of the elliptical wave and

$\mathrm{V}_{\mathrm{m}} \quad$ - is the amplitude of the elliptical wave.

' $h$ ' and ' $k$ ' are the $X$ and $Y$ coordinates of ellipse's center

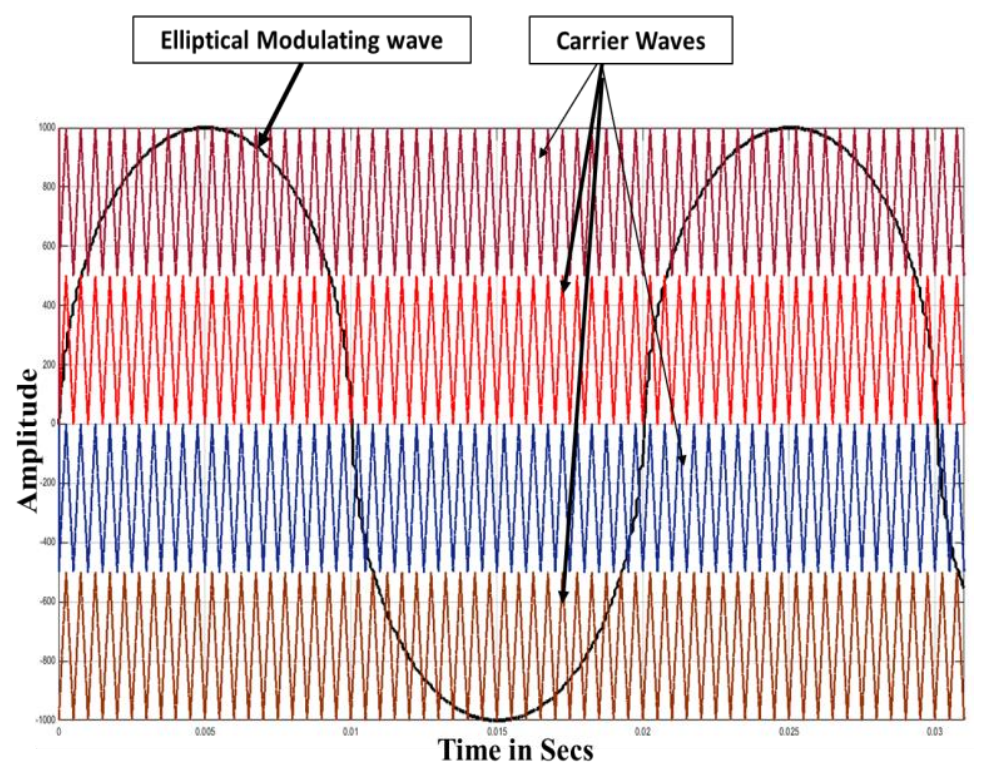

Figure 9. Carrier waves comparison with Elliptical modulating wave in EPD PWM Technique for five level CHBMLI. 


\subsection{Control Techniques for Grid connected Inverters}

While connecting the solar power inverters to the grid distributed generation system, a number of problems arises and hence to overcome this situation, a suitable controller must be selected for it. Based on the applications, various control strategies are discussed in the literature for voltage, current and power droop control [38]-[41]. Usually the inner loop regulates the current and outer loop regulates the voltage. The classical linear controllers include proportional (P), proportional integration (PI), proportional derivative (PD), proportional integral derivative (PID). In these controllers PID values are tuned according to the preset values of the plant and they are simple in structure. In Figure 10, the classification of control technique for grid connected inverters is shown. The hysteresis controllers which are nonlinear controllers and they are used to measure the error between the refrence and actual currents. For error removal refrence tracking, the Hysterisis bandwidth is adjusted. Sliding mode control is a nonlinear technique, whereas it can be instigated to both linear systems and nonlinear. The Fuzzy and Artificial Neural Network (ANN) control techniques comes under the intelligent control technique. In a fuzzy controller, the inputs are given as the tracking error of load current and its derivative. To perform as a biological human brain, ANN comprises a number of artificial neurons. To generate the switching signals for the power converters, the reference tracking error signals are given through a suitable gain as input to the ANN. The combination of Fuzzy and ANN results in an optimal control performance in a power converter. The predictive controllers are classified into deadbeat control and model predictive control.

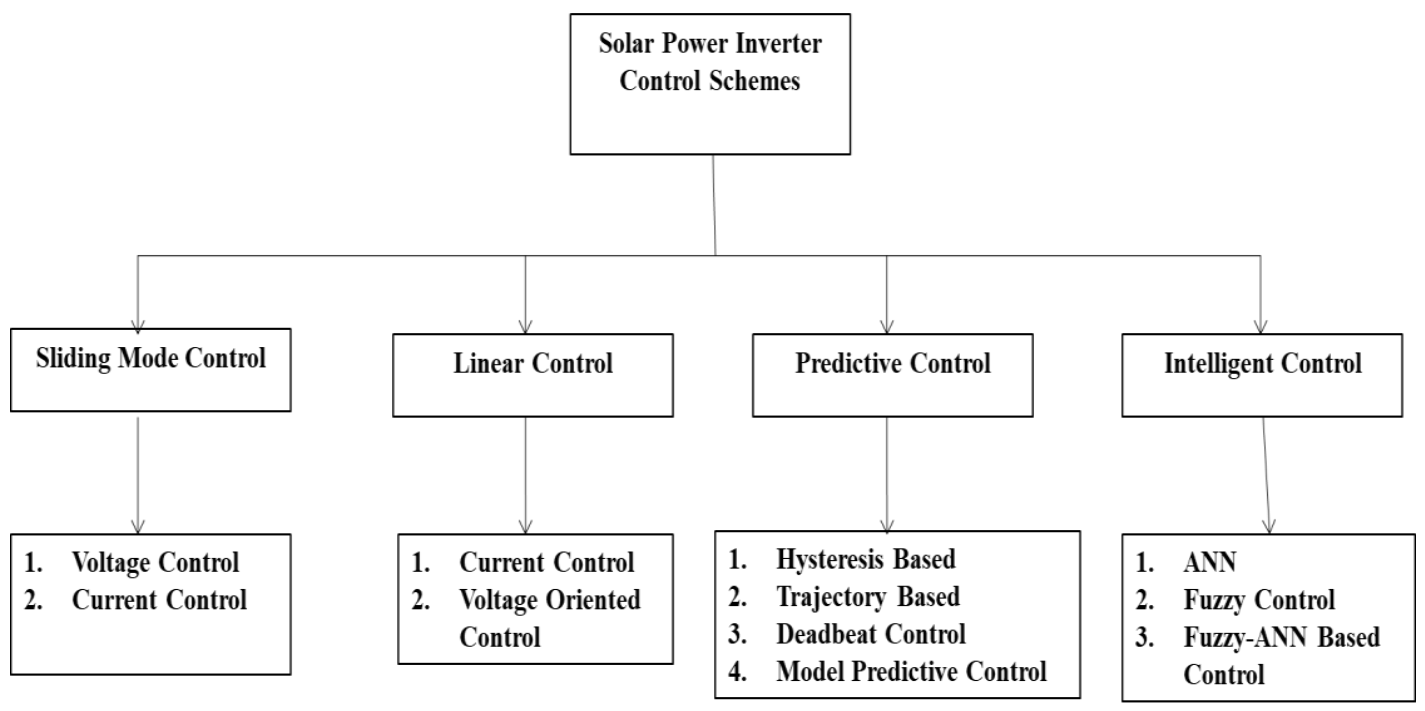

Figure 10. Classification of Control Techniques for Grid connected Inverters 


\section{SUMMARY OF LITERATURE REVIEW}

In fundamental switching frequency modulation technique, that is SHE technique, superior output quality is achieved with direct control over the output voltage harmonics. Also the switching losses are less as the SHE techniques operate at fundamental frequency. Major drawback of this technique is to solve highly non-linear transcendental equations to calculate the switching angles it takes more time to calculate. From several years, it has been a challenging research wrok to provide analytical solution for full range of modulation index. The low order harmonics other than selected will be present in the output. As this technique is offline control, dynamic control is not possible [22].

The SPWM technique is very simple and easy to extend for high level output of inverters. Computational time and implementation time is less compared to SHE and SVPWM technique. This PWM technique can operate at both fundamental and high switching frequencies. The harmonic profile of the output is also good compared to SHE technique. The drawback of this modulation technique is poor utilization of DC bus and also it cannot eliminate low order harmonics completely [30].

To improve the DC bus utilization, the pure sine modulating wave has to be added with third harmonic component. This results in increase of fundamental component of output to increase by 15\% than pure sine wave technique. Third harmonic injection PWM technique most of the time, suits for three-phase inverter. The drawback of this THIPWM is that the modulating waveform has to be continuous irrespective of the shape, as a consequence switching frequency will be more compared to SPWM technique [31].

The SVPWM technique is having superior performance compared to SHE technique and SPWM technique with respect to output voltage quality where it produces nearly $15.5 \%$ more voltage than other two. DC bus utilization is better than SPWM without over modulation [21]. The drawback of SVPWM technique is, increase in number of redundant switching states, leading to difficulty in selecting the switching states. Also, SVPWM technique is unable to eliminate low order harmonics. Basically SVPWM suits only for controlling three-phase inverter. SVPWM technique has been implemented practically only up to 5-level of output voltage [22].

The various EMC PWM techniques simulated results in increased output voltage. From simulation and hardware implementation results shows that the EMC PWM technique works very competently improving DC bus utilization around the peak of the output voltage and increase the AC output by $15 \%$ compared to traditional MCPWM technique. This increase in the performance is achieved without "over-modulation" and without "third harmonic injection" to modulating wave. EMC PWM control startegy is less complex and can be extended to higher level of MLI [35 ] - [36]. 
For low power installation of PV systems connected to the grid, PWM is a widely used technique for controlling the voltage source inverters. The current controller of power converters can be a closed loop PWM, such as "Hysteresis Current Control, linear PWM, predictive controllers, optimized controllers, neural network and fuzzy logic controller systems". Among these control methods, hysteretic control is simple but due to variable switching frequency it has a current ripple. Proportinal controllers are most commonly used to control the single phase inverters but they need tuning of the control gains generally. The Intelligent controllers such as "neural networks, sliding mode and fuzzy control methods", which are used for single phase grid connected inverter have a complex calculation burden. "Predictive controllers" are fast, robust, and easy for digital implementation. These controllers calculates the value of inverter voltages to make the output currents to follow the reference current [38][40]. For grid connected PV single phase inverter; there are two common switching strategies, these are Bipolar and Unipolar PWM switching. To control the injected current in phase with the grid voltage, the controller uses the digital unipolar DPWM patterns [41].

\section{CONCLUSION}

Among the three MLI topologies, cascaded H-bridge inverters are most preferred toplogy for various applications which have simple switching logic, modular structures and simple power circuits. It does not have dynamic voltage sharing problem. Hence, CHBMLI topology as ideal for isolated power supplies, which is the case in PV cells, fuel cells and battery powered UPS.

Although different PWM techniques are available for control of CHBMLI, MCPWM technique is one of the efficient control strategy often employed in the literature, as it is very easy to implement even for higher output level of MLI. The quality of the output voltage can be still increased if the DC bus utilization is improved.

The EMC PWM control strategy is the new modulation technique which is very successful in improving the DC bus utilization in MCPWM technique. The EMC PWM technique achieves improved DC bus utilization by not using over-modulation and addition of third harmonic to fundamental frequency. Also, the technique is successful in decreasing the \%THD at the inverter output voltage. The complexity of the control strategy will not increase much for the increased level of output voltage, which is not possible in SVPWM technique. Hence, the EMC PWM technique is having better performance when compared to MCPWM technique, SVPWM technique and THIPWM technique. 


\section{REFERENCES}

[1] Off-grid Renewable Energy in India Technology \& Service Overview 2015 - 2016, Indo-German Energy Forum Support Office, Second Edition, pp-10, March 2015.

[2] G.D. Kamalapur, and R.Y. Udaykumar, Rural Electrification in India and feasibility of Photovoltaic Solar Home Systems, Electrical Power and Energy Systems 33, Elsevier Ltd., doi:10.1016, IJEPES, pp.594-599, 2011

[3] Article,) Solar tariff bottoms out, may not have free fall in 2018https://timesofindia.indiatimes.com/business/india-business/solartariff-bottoms-out-may-not-have-free-fall-in2018/articleshow/62400667.cms

[4] Article, Where are Indian solar tariffs headed?http://www.solarquarter.com/index.php/7882-where-are-indiansolar-tariffs-headed

[5] Deepak Paramashivan Kaundinya, P. Balachandra, N. H. Ravindranath, Grid-connected versus stand-alone energy systems for decentralized power-A review of literature, Elsevier- Renewable and Sustainable Energy Reviews, vol. 13, pp.2041-2050, 2009.

[6] Venkatachalam Kumar Chinnaiyan, Jovitha Jerome and J. Karpagam , An Experimental Investigation on a Multilevel Inverter for solar energy applications, Electrical Power and Energy Systems, , ELSEVIER, Vol.47, pp.157-167, 2013.

[7] Nupur Mittal, Bindeshwar Singh, S.P. Singh, , Rahul Dixit and Dasharath Kumar, Multilevel Inverters: A Literature Survey on Topologies and Control Strategies, 2nd IEEE International Conference on Power, Control and Embedded Systems, ISSN: 978-1-4673-1049-9, DOI: 10.1109/ICPCES.2012.6508041, Allahabad, India,2012.

[8] Abdelaziz Fria, Rachid El Bachtiria, Abdelaziz El Ghzizala, A Comparative Study of Three Topologies of Three-Phase (5L) Inverter for a PV System, Energy Procedia, Vol. 42, pp.436 - 445, 2013.

[9] Zheng Zeng, Huan Yang, Rongxiang Zhao, Chong Cheng, Topologies And Control Strategies of Multi-Functional Grid-Connected Inverters for Power Quality Enhancement: A Comprehensive Review, Elsevier Renewable and Sustainable Energy Reviews, Vol.24, pp.223-270, 2016.

[10] Hamidreza Keyhani, Matthew Johnson and Hamid A. Toliyat, A SoftSwitched Highly Reliable Grid-Tied Inverter for PV Applications, Twenty-Ninth Annual IEEE- Applied Power Electronics Conference and Exposition (APEC), 16-20 March 2014, 1725 - 1732.

[11] Fracchia, M, Ghiara, T, Marchesoni, M and Mazzucchelli, M, Optimized Modulation Techniques for the Generalized N-level Converter, Proceedings of the IEEE Power Electronics Specialist Conference, Vol.2, 1205-1213, 1992. 
[12] Venkatachalam Kumar Chinnaiyan, Jovitha Jerome and J. Karpagam, An Experimental Investigation on a Multilevel Inverter for solar energy applications, Electrical Power and Energy Systems, Vol. 47C, 2013, pp.157-167. DOI information: 10.1016/j.ijepes.2012, pp.157-167, 2013.

[13] Panagiotis Panagis, Fotis Stergiopoulos, Pantelis Marabeas and Stefanos Manias, Comparison of State of the Art Multilevel Inverters, IEEE Power Electronics Specialists Conference, PESC., ISSN: 0275-9306, pp.4296 - 4301, 2008.

[14] Sergio Daher, Jurgen Schmid and Fernado L.M. Antunes, Multilevel Inverter Topologies for Stand-Alone PV Systems,I EEE Transactions on Industrial Electronics, Vol. 55, No. 7, 2703-2712, July 2008.

[15] I. D. Pharne, and Y.N. Bhosale, A Review on Multilevel Inverter Topology, IEEE International Conference on Power, Energy and Control(ICPEC)-2013, ISSN: 978-4673-6030-2, pp. 700-704, 2013.

[16] Muhammad H. Rashid, Power electronics-Circuits, Devices and Applications, Third Edition, Pearson Publication, pp.411-422.

[17] Jun Mei, Balio Xiao, M. Leon, and Jian Yong, Modular Multilevel Inverter with New Modulation Method and Its Application to Photovoltaic Grid-Connected Generator, IEEE Transactions on Power Electronics, Vol. 28, No.11, pp.5063-5073, Nov 2013

[18] A.R. Beig, and A. Dekka, Experimental Verification of Multilevel Inverter-Based Standalone Power Supply for Low-Voltage and Low-Power Applications, IET Power Electronics, Vol. 5, No.6, pp. 635643, 2012.

[19] Yi-Hung Liao and Ching-Ming Lai, Newly-Constructed Single-Phase Multistring Multilevl Inverter Topology for Distributed Energy Resources, IEEE Transactions on Power Electronics, Vol. 26, No. 9, pp. 2386 - 2392, Sept. 2011.

[20] Joshi Manohar Vesapogu1, Sujatha Peddakotla and Seetha Rama Anjaneyulu Kuppa, Harmonic Analysis and FPGA Implementation of SHE Controlled Three- Phase CHB 11-level Inverter in MV Drives Using Deterministic and Stochastic Optimization Techniques, SpringerPlus volume 2, Article number: 370, 2013.

[21] R. Vijay Kumar, Alamelu Natchiappan, C. Devilalitha, , R. Mazhuventhi, Selective Harmonic Elimination PWM Method using Seven Level Inverters by Genetic Algorithm Optimization Technique, International Journal of Engineering Research \& Technology (IJERT), Vol. 4, No.2, pp. 812-818, Feb 2015.

[22] Keliang Zhou and Danwei Wang, (2002) Relationship Between SpaceVector Modulation and Three-Phase Carrier-Based PWM: A Comprehensive Analysis, IEEE Transactions On Industrial Electronics, Vol. 49, No. 1, pp. 186-196, Feb 2002.

[23] Hemant Gupta, Arvind Yadav, Sanjay Maurya, (2016) Multi Carrier PWM and Selective Harmonic Elimination technique for Cascade 
Multilevel Inverter, IEEE- International Conference on Advances in Electrical, Electronics, Information, Communication and Bio-Informatics (AEEICB16), Chennai, India, 978-1-4673-9746-9, pp. 1-5, Feb 2016.

[24 ] Bogimi Sirisha, P. Satish Kumar,) A Simplified Space Vector Pulse Width Modulation Method Including Over Modulation Operation for Five Level Cascaded H-bridge Inverter with FPGA Implementation, International Journal of Power Electronics and Drive System (IJPEDS), Vol. 8, No. 3, pp. 1203-1211, Sept 2017.

[25] K. Vinoth Kumar, Prawin Angel Michael, Joseph P. John and S. Suresh Kumar, Simulation And Comparison Of SPWM And SVPWM Control For Three Phase Inverter, ARPN Journal of Engineering and Applied Sciences, ISSN 1819-6608, Vol. 5, No. 7, July 2010.

[26] B.G. Shivaleelavathi, E.G. Shivakumar, Optimal SVPWM Signal Generation for three level Inverters, IEEE International Advance Computing Conference -IACC-2009, 1362-1369, March 2009.

[27] Ville Naumanen, Multilevel Converter modulation: Implementation and Analysis, Thesis for the degree of Doctor of Science (Technology), Lappeenranta University of Technology, Finland, June 2010.

[28] Shantanu Chatterjee, A Multilevel Inverter Based on SVPWM Technique for Photovoltaic Application, International Journal of Power Electronics and Drive Systems (IJPEDS), , ISSN: 2088-8694, Vo1. 1, pp. 67-73, March 2013.

[29] John Alan Vodden, Modulation techniques for the Cascaded H-bridge Multi-Level Converter, Ph. D thesis, University of Nottingham, July 2012.

[30] Rasoul Shalchi, Seyyed Hossein Hosseini, A New Multilevel Inverter Structure for High-Power Applications Using Multicarrier PWM Switching Strategy, International Journal of Power Electronics and Drive Systems (IJPEDS), ISSN: 2088-8694, , Vol. 6, No. 2, pp.318-325, June 2015.

[31] Phuong Hue Tran, (2012) MATLAB/Simulink Implementation And Analysis of Three Pulse-Width-Modulation (PWM) Techniques, Thesis of Master of Science in Electrical Engineering Boise State University, May 2012.

[32] Wanchai Subsingha, (2016) A Comparative Study of Sinusoidal PWM and Third Harmonic Injected PWM Reference Signal on Five Level Diode Clamp Inverter, Energy Procedia, Vol. 89, pp.137 - 148, 2016.

[33] Chinmayi, B.G. Shivaleelavathi, Enhancement of Fundamental RMS Output Voltage of 5-level Cascaded H-Bridge Multilevel Inverter Using Modified Multicarrier PWM Technique, IJEET, Vol. 7, No. 1, pp. 17-29, Jan-Feb 2016.

[34] Chinmayi, B.G. Shivaleelavathi, Performance Analysis of Cascaded Multilevel Inverter Using Modified Multicarrier PWM Technique, in Proceedings. IEEE ICIMIA 2017, Bengaluru, India, 978-1-5090-5960-7, pp. 50-55, 21 $1^{\text {st }}-23^{\text {rd }}$ Feb 2017. 
[35] Chinmayi, B. G. Shivaleelavathi, A Novel Implementation of Digital Control Strategy for Multilevel Inverters Using FPGA Wavect Controller, IEEE COMPEL 2017, Stanford University, California, USA, ISSN : 978-1-5090-5326-1, pp.1-6, 9th -12th July, 2017.

[36] Chinmayi, B. G. Shivaleelavathi, Digital Control of Three-Phase Cascaded Multilevel Inverter Using FPGA Wavect Tool, International Journal of Power Electronics and Drive System (IJPEDS), ,Vol. 9, No. 1, 189-197, March 2018.

[37] Chinmayi, B. G. Shivaleelavathi, Veeramma Yatnalli, Simulation of Seven and Nine Level CHBMLI with Elliptical Phase Disposition PWM Technique, Scientific Research Publishing- JPEE, ISSN: 23275901,Vol. 8, pp. 49-63, March 2020

[38] Sohaib Tahir, Jie Wang, Mazhar Hussain Baloch and Ghulam Sarwar Kaloi, Digital Control Techniques Based on Voltage Source Inverters in Renewable Energy Applications: A Review, Electronics, MPDI, 1-37, doi:10.3390/electronics7020018,Feb 2018

[39] Esmaeil Zangeneh Bighasha, Seyed Mohammad Sadeghzadeha,Esmaeil Ebrahimzadehb, Frede Blaabjergb, High quality model predictive control for single phase grid-connectedphotovoltaic inverters, Electric Power Systems Research, Elsevier 158, ISSN: 0378-7796, pp. 115-125, Feb 2018

[40] L. Hassaine a,n, E. OLias b, J. Quintero b, V. Salas b, Overview of power inverter topologies and control structures for grid connected photovoltaic systems, Renewable and Sustainable Energy Reviews, Elsevier 30, ISSN: 1364-0321, pp.796-907, 2013

[41] Linda Hassaine*, Mohamed Rida Bengourina, Control technique for single phase inverter photovoltaic system connected to the grid, Energy Reports 6, Elsevier ScienceDirect, ISSN: 2352-4847, pp. 200208, 2020 